Avrupa Bilim ve Teknoloji Dergisi

Özel Sayı, S. 28-36, Kasim 2020

(C) Telif hakkı EJOSAT'a aittir

Arasturma Makalesi
European Journal of Science and Technology

Special Issue, pp. 28-36, November 2020

Copyright C 2020 EJOSAT

$\underline{\text { Research Article }}$

\title{
Soğutma Sistemlerindeki Soğutucu Akışkan Kaçak Tespiti İçin Kızılötesi Görüntüler Üzerinde Pearson Korelasyon Benzerlik Analiz Yönteminin Kullanılması
}

\author{
Ferzan Katırcıoğlu ${ }^{1}$, Zafer Cingiz ${ }^{2 *}$, Yusuf Çay ${ }^{3}$, A. Etem Gürel ${ }^{4}$, Ahmet Kolip ${ }^{5}$ \\ ${ }^{1}$ Düzce Üniversitesi, Düzce MYO, Elektronik ve Otomasyon Bölümü, Düzce, Türkiye (ORCID: 0000-0001-5463-3792) \\ 2 Düzce Üniversitesi, Düzce MYO, Elektrik ve Enerji Bölümü, Düzce, Türkiye (ORCID: 0000-0003-3796-755X) \\ ${ }^{3}$ Sakarya Uygulamalı Bilimler Üniversitesi, Teknoloji Fakültesi, Makine Mühendisliği Bölümü, Sakarya, Türkiye (ORCID: 0000-0003-4007-6168) \\ ${ }^{4}$ Düzce Üniversitesi, Teknoloji Fakültesi, Makine Mühendisliği Bölümü, Düzce, Türkiye (ORCID: 0000-0003-1430-8041) \\ ${ }^{5}$ Sakarya Uygulamalı Bilimler Üniversitesi, Teknoloji Fakültesi, Makine Mühendisliği Bölümü, Sakarya, Türkiye (ORCID: 0000-0001-6666-1141)
}

(International Symposium on Multidisciplinary Studies and Innovative Technologies (ISMSIT) 2020 - 22-24 Ekim 2020)

(DOI: 10.31590 /ejosat.818440)

ATIF/REFERENCE: Katırcıŏlu, F., Cingiz, Z., Çay, Y., Gürel, A. E. \& Kolip, A. (2020). Soğutma Sistemlerindeki Soğutucu Akışkan Kaçak Tespiti İçin Kızılötesi Görüntüler Üzerinde Pearson Korelasyon Benzerlik Analiz Yönteminin Kullanılması. Avrupa Bilim ve Teknoloji Dergisi, (Özel Sayı), 28-36.

Özet

Soğutma sistemlerinde soğutucu akışkan kaçakları montaj ve servis hatalarından kaynaklanabildiği gibi, zaman içinde boru ve bağlantılardaki titreşime ve malzeme yıpranmasına bağlı olarak oluşabilmektedir. Bu durum, soğutma sisteminin çalışma verimini engelleyerek, soğutma/ısıtma kapasitesini düşürme ve sistemde kızgınlık artışına neden olmaktadır. Ayrıca, emme hattında vakum düşüşü gerçekleşeceği için sisteme hava ve nem girişinden dolayı iç kirlenme ve tıkanma oluşmaktadır. Soğutucu akışkan kaçaklarının tespitinde köpükleme ve akışkan kaçak dedektörü ile algılama kullanılan en yaygın yöntemlerdir. Bu çalışmada, bir soğutma sisteminde oluşabilecek kaçakların tespiti için, kızılötesi görüntü işleme tekniğine dayalı yeni bir yöntem önerilmiştir. Bunun için ilk olarak, R22 soğutucu akışkan kullanılarak hazırlanan deney düzeneğinde, 7 farklı noktada, farklı zamanlarda yapay kaçaklar oluşturulur. Daha sonra, sağlam sistem kızılötesi görüntüsü ile yapay kaçak yapılmış sistem görüntüleri üzerinden daha önceden tespit edilmiş 12 alt bölgeden öznitelik verileri çıkartılmaktadır. Öznitelik özellik verilerinin elde edilme işleminde, belirlenen 12 bölgenin yüzey sıcaklık bilgileri kullanılmıştır. Yüzey sıcaklık bilgileri minimum, maksimum, ortalama ve en yoğun sıcaklık bilgisi olarak dört farklı şekilde çeşitlendirilmiştir. Kızı̈ötesi görüntü analizi işlemini gerçekleştirmek için elde edilen öznitelik verileri Pearson Korelasyon Benzerlik Analizi (PKBA) işlemine sokulmaktadır. Son olarak, izlenmesi gereken 12 alt bölgenin PKBA sonuçları bir eşik değere tabi tutularak, eşik değerin altında kalan bölgelerde "Kaçak vardır" tespiti yapılmaktadır. Diğer bir olası durum ise, eğer sağlam ve kaçak kızılötesi karşılaştırmasında, benzerlik değerinin çok yüksek bir değer oluşmasında, bu bölgeler için "Kaçak yoktur” sonucunu vermektedir. Kızılötesi görüntü işleme tekniği kullanılarak gerçekleştirilen PKBA ile kaçak tespit işlemi, kullanım kolaylığı, hızlı ve eş zamanlı kaçak tespit etme noktasında daha avantajlı olduğunu göstermiştir.

Anahtar Kelimeler: Soğutucu akışkan kaçak tespiti, Kızılötesi görüntü işleme, Pearson Korelasyon Benzerlik Analizi

\section{Using Pearson Correlation Similarity Analysis Method on Infrared Images to Detect Refrigerant Leakage in Refrigeration Systems}

\begin{abstract}
Refrigerant leaks in refrigeration systems can be caused by assembly and service failures, as well as due to vibration and material wear in pipes and connections over time. This situation prevents the working efficiency of the refrigeration system, decreasing the cooling/heating capacity and causing an increase in superheating in the system. In addition, internal contamination and clogging occurs due to air and humidity entry into the system, as there will be a vacuum drop in the suction line. Foaming and detection with fluid
\end{abstract}

\footnotetext{
* Sorumlu Yazar: Düzce Üniversitesi, Düzce MYO, Elektronik ve Otomasyon Bölümü, Düzce, Türkiye, ORCID: 0000-0001-5463-3792, ferzankatircioglu@duzce.edu.tr
} 
leakage detector are the most common methods used to detect refrigerant leakages. In this study, a new method based on infrared image processing technique was proposed to detect leakages that may occur in a refrigeration system. For this, firstly, in the experimental setup prepared using R22 refrigerant, artificial leakages are created at 7 different points and at different times. Afterwards, feature data are extracted from 12 sub-regions previously determined by using the robust system infrared image and artificially illegal system images. In the process of obtaining feature property data, the surface temperature information of 12 sub-regions determined was used. Surface temperature information has been diversified in four different ways as minimum, maximum, average and most intense temperature information. In order to perform the infrared image analysis process, the feature data obtained are entered into the Pearson Correlation Similarity Analysis (PCSA) process. Finally, the PCSA results of the 12 sub-regions that need to be monitored are subjected to a threshold value and the regions below the threshold value are detected as "There is leakage". Another possible situation is that if the similarity value is very high in the comparison of robust and artificially illegal system infrared, it gives the result "No leakage" for these regions. Leakage detection with PCSA using infrared image processing technique has shown that it is more advantageous in terms of ease of use, fast and simultaneous leakage detection.

Keywords: Refrigerant leakage detection, Infrared image processing, Pearson Correlation Similarity Analysis

\section{Giriş}

Evsel ve ticari soğutma ile iklimlendirme sistemleri, dünya üzerinde gelişmiş modern hayatın vazgeçilmez bir parçasını oluşturmaktadır. Bozulabilen ürün ve maddelerin korunması, endüstrilerde sıcaklık ile ilgili süreçlerin düzenlenmesi ve konforlu bir ortam sağlanması bu sistemlerin kullanımının çok yaygın olduğunu göstermektedir.

Bir soğutma ve iklimlendirme sisteminde soğutucu akışkan kaçağı en sık karşılaşılan arıza olup, sistemin verimi açısından tespiti son derece önemlidir. Ani oluşan kaçaklar kolaylıkla tespit edilebilir, ancak yavaş ve uzun süreli oluşan kaçakların tespit edilmesi zordur. Büyük ölçekli soğutma sistemleri, kaçağı tespit etmek veya teşhis etmek için yeterli miktarda veriye sahiptir. Ancak küçük ve orta ölçekli sistemlerde kaçağın tespit edilmesi işlemi zorlaşmaktadır.

Literatür incelendiğinde soğutucu akışkan kaçakları üzerine yapılmış çalışmaları gruplandırmak mümkündür. Performans ve soğutma kapasitesine etkisi bakımından yapılan çalışmalar şu şekildedir. Poggi ve diğ. yaptıkları çalışmada, bir soğutma sistemindeki soğutucu akışkan şarj işlemlerinin gözden geçirilmesini sunmaktadır. Ayrıca, soğutucu akışkan şarjının, performans katsayısı (COP) ve soğutma kapasitesi üzerindeki etkisi de değerlendirilmektedir (Poggi, 2008). Goswani yaptığı çalışmada, toplam soğutucu akışkan miktarında \%10'luk bir azalmasının, maksimum COP ‘a kıyasla \%3,5'lük bir soğutma kapasitesi azalması ve \%2'lik bir COP artışı oluşturduğunu göstermiştir (Goswami, 2001). Corberán ve diğ. yaptıkları çalışmada, soğutucu kaçağı meydana geldiğinde COP ve soğutma ile ısıtma kapasitesinde ciddi oranda azalma meydana geldiğini gözlemlemiştir. Bu nedenden dolayı, konut tipi klimaların soğutucu akışkan miktarını tespit etmek önemlidir (Corberán, 2011).

Küresel ısınma ve çevresel etki ile elektrik tüketimi açısından bakıldığında yapılan çalışmalar şu şekildedir. Birleşik Krallık'ın büyük süpermarket zincirlerinden ikisinde soğutucu akışkan sızıntısına ait 1464 adet bakım kayıt raporundaki sızıntı verileri analiz edilmiştir. Analiz, onarım sırasında oluşan her bir sızıntının türünü, yerini ve soğutucu akışkan hacmini gruplandırmıştır. Kaydedilen kaçakların \%82'sinden fazlası boru veya bağlantı arızaları ile kompresör ünitesinde ya da yüksek basınçlı sıvı hattında bulunan bir sızıntı contas1/ yağ keçesinden oluştuğu belirlenmiştir (Francis, 2017). Soğutma sistemlerinden soğutucu akışkan kaçağ1 çevreyi hem küresel 1sınma potansiyeli nedeniyle doğrudan etkilemekte hem de enerji tüketiminin artmasına yol açarak soğutma sisteminin verimliliğinin azalması (şarj kaybı nedeniyle) nedeniyle dolaylı şekilde etkilemektedir (Grace, 2005). Klimanın elektrik enerjisi tüketimindeki artış, freon sızıntısı ve kirli hava filtresinden kaynaklanabilmektedir. Freon sızıntısı meydana geldiğinde ve hava filtresi kirlendiğinde, sistem kompresörü, sıcaklık istenilen bir ayar noktası sağlanıncaya kadar sürekli çalışacağından elektrik tüketiminde artış olacaktır. Bu çalışmada, freon gazı sızıntısı oluştuğunda ve hava filtresi kirlendiğinde, klima kullanıcısının sorunu tespit edip bilgilendirebilecek bir kontrol sisteminin nasıl kurulacağı anlatılmıştır (Ramschie, 2017). Koranaki ve diğ., yaptıkları çalışmada, RealSkillsEurope projesinde, soğutucu akışkan emisyonlarının çevre üzerindeki etkisinin ve iklim değişikliğiyle olan güçlü ilişkisi vurgulanmıştır. Bu projede, $\mathrm{AB}$ üye ülkelerine sadece çevresel etki ve iklim değişikliği ile ilgili sorunlarla başa çıkmak için değil, aynı zamanda soğutucu akışkan kaçaklarının önlenmesi ile ilgili yöntemlerin ele alınması gerektiği belirtilmiştir. Proje ayrıca ortak ülkelerdeki ulusal yasalar ve Avrupa yasalarında belirtilen soğutucu akışkan kaçaklarının miktarını ve bunların yönetim yöntemlerini belirlemeye çalışmıştır (Koronaki, 2012). Avrupa Yönetmeliği 1516/2007, 3 kg'dan fazla soğutucu gaz içeren tüm ekipman ve/veya tesisler için periyodik muayeneler yapma yükümlülügünü belirlemiştir. Tesisler, yılda 5 g'lık hata hassasiyeti olan bir kaçak dedektörü tarafindan periyodik olarak kontrol edilmelidir. Çoğu durumda bu sızıntı testlerini vakum koşullarında yapmak uygun değildir. Bu nedenle, testler atmosfer basıncında kaçak dedektörü ile yapılmalıdır (Union, 2007). Arızaların erken tespiti, sektörde önemli bir konu olarak büyük ilgi görmektedir. Sistemin en temel arıza sorunu, boruların çatlaması veya bozulmasından kaynaklanan soğutucu akışkan kaçaklarıdır. İç ortam sıcaklık ayarlamasını engellemenin yanı sıra, soğutucu akışkan kaçaklarının çevresel kirlenmeye neden olduğu iyi bilinmektedir (Koronaki, 2012) (Mota-Babiloni, 2015). Rossi yaptığı çalışmada, soğutucu akışkan kaçağının klimaların sıcaklık ayarlamadan dolayı oluşan arızalarının \%63'ünü oluşturduğunu göstermiştir (Rossi, 2004). Madani ve diğg. yaptıkları çalışmada, hava kaynaklı ısı pompalarının arıza maliyetlerinin \%17'sinin soğutucu akışkan kaçaklarından kaynaklandığını belirtmişlerdir (Madani, 2014). Bir sistemin toplam karbon emisyonları, hem sistemden kaçan soğutucu akışkanın etkisini hem de bir sistemin güç tüketimini içermektedir. Elektrik tüketimi, sisteme soğutucu akışkan şarjı yapılması ve sık şekilde servis hizmetlerinden dolayı çalışma maliyetinin arttığını tespit etmiştir. Bunun yanında, sistem verimliliği düşeceği için elektrik tüketimi ve $\mathrm{CO}_{2}$ emisyonları artacağından dolayı iklim değişikliği üzerinde dolaylı etki yapacaktır. Ayrıca, tüm bunların yanında iklim değişikliğine doğrudan etkide bulunacaktır (project R. S., tarih yok) (project R. Z., tarih yok). 
Sıcaklık ve basınç verileri değerlendirilerek yapılan çalışmalar şu şekildedir. Koçyiğit ve diğ. yaptıkları çalışmada, p-h diyagramı buhar sıkıştırmalı soğutma çevrimindeki arızaları teşhis etmek için kullanılmıştır. Uzman bir kişi, soğutma sistemlerinde oluşabilecek daha fazla arızayı yorumlayabilecektir. Çalışmada, tanının uygulanmasını göstermek için sekiz yapay arıza içeren deney düzeneği kullanılmıştır. P-h diyagramlarındaki çevrim ile normal ve arızalı koşullar arasındaki farkın kolayca gözlemlenebileceği onaylanmıştır (Kocyigit, 2014). Braun yaptığı çalışmada, kondenserde oluşan kirlenmenin ve yetersiz soğutucu akışkanın termodinamik ölçümler üzerindeki benzersiz etkileri ile ayırt edilebileceğini göstermiştir (Braun, 2003).

Sensör ve bilgisayar da veri işleme yöntemleri kullanılarak yapılan çalışmalar şu şekildedir. Takeuchi ve diğ. yaptıkları çalışmada, sisteme monte edilmiş sensör verileri kullanılarak erken arıza tespitinin, endüstriyel tesislerde makine öğreniminin umut verici uygulama alanlarından biri olduğu vurgulanmıştır. Burada, soğutucu akışkan kaçağı tespiti için bir arıza teşhis yöntemi önerilmiştir. Gerçek proses verilerinin kaçak derecesinin zaman serisini ölçeklendirme kuralına göre tahmin edilerek ve önerilen yöntemin, uzmanlar tarafindan yapılan değerlendirmeyle karşılaştırılarak erken kaçak tespiti için umut verici olduğu doğrulanmıştır (Takeuchi, 2018). Tassou ve diğ. yaptıkları çalışmada, yapay sinir ağı kullanarak buhar sıkıştırmalı soğutma sistemindeki soğutucu akışkan kaçağını tahmin etmişlerdir. Şarj miktarın tahmin etmek için deneysel yöntemler genellikle çok doğrudur, ancak sisteme bağl oldukları için tek bir sisteme uygulanabilmektedirler. Ampirik yöntem ayrıca büyük miktarda veri gerektirmektedir. Pek çok büyük sistemde, soğutucu akışkan yükünün \% 20'sinden fazlasının her yıl atmosfere salınarak ozon tabakasının incelmesine ve küresel ısınmaya katkıda bulunduğu tahmin edilmektedir (Tassou, 2005). Yoo ve diğ. yaptıkları çalışmada, iki sensör bilgisini kullanarak bir ev tipi klimada soğutucu akışkan kaçağını tespit etmek için bir yöntem önermişlerdir. Bu çalışmada, deneysel verilere dayalı olarak, sınırlı sensör bilgisine sahip elektronik genleşme vanası monte edilmiş konut tipi klimalar için bir soğutucu akışkan kaçağı tespit yöntemi önerilmektedir. Bu yöntem, giriş havası ve ısı eşanjörünün orta noktası arasındaki sıcaklık farklarını kullanır. Çeşitli sıcaklık koşulları için, sıcaklık farkı, iyi bir kaçak tespit prosedürü olarak kullanılabilecek benzer bir eğilim göstermektedir (Yoo, 2017). Son yıllarda gerçekleştirilen Katırcıoğlu ve diğ. yaptığı çalışmada, soğutma sistemlerinde termal görüntü analizi ile farklı soğutucu akışkanların uzaktan sensörsüz olarak performanslarının karşılaştırılması için, elde edilen termal görüntülerin iyileştirilmesi önerilmiştir (Katırcioğlu, 2019).

Sisteme yeterli miktarda soğutucu akışkan şarj edilmemiş ya da sistemden bir şekilde soğutucu akışkan kaçağı gerçekleşmiş ise, soğutma ve 1sıtma kapasitesi ile COP'da büyük ölçüde azalma meydana gelmektedir. Soğutma sisteminde optimum şarj miktarının uygulanması çok önemlidir. Çünkü soğutucu akışkan kaçağına bağlı olarak performansta düşüş oluşmaktadır. HCFC ve HFC soğutucuların doğrudan sera etkisine önemli etkilerinden dolayı, atmosferik emisyonlarını azaltmak acildir. Bu nedenle, sistemlerdeki kaçakların azaltılmasını sağlamak önemli bir hedeftir. Buhar sıkıştırmalı soğutma sistemlerinde, arızaların oluşmasından kaynaklanan performans düşüklüğü nedeniyle enerji tüketiminde büyük ölçüde bir artış söz konusu olmaktadır. Soğutma sistemleri, konut ve ticari binalardaki elektrik enerjisi tüketiminin büyük bir kısmını oluşturduğundan, arızaların tespit edilerek çözüme ulaştırılması ve bu arızaları başlangıçta tespit edebilen sistemlerin geliştirilmesi, ekonomik ve çevresel etkiye sahip olabilecek maliyet ve enerji tasarruflarını sağlayabilecektir. Bu çalışmanın amacı, soğutucu akışkan kaçaklarının hızlı ve uzaktan tespiti için kızılötesi görüntü işleme tekniği kullanılan bir yöntem gerçekleştirmektir. Literatürdeki ve genel uygulamalarda kullanılan yöntemlere göre birden fazla noktada kaçak tespiti ve her türlü soğutucu akışkan içinde kullanılabilir olması önerilen yöntemin en büyük üstünlükleridir.

\section{Materyal ve Metot}

Deney düzeneği olarak buhar sıkıştırmalı soğutma çevrimi esasına göre, R22 soğutucu akışkanı ile çalışmakta olan ticari tip bir soğutma sistemi tasarlanmıştır. Tasarlanan deney sisteminde kullanılan ekipman ile yapay kaçak noktalarının ve termal kameranın pozisyonları Şekil 1'de gösterilmiştir.

Soğutma sisteminin ve kullanılan soğutucu akışkanın kaçak noktalarını görüntü işleme yöntemiyle değerlendirmek amacıyla sistemden görüntüler alınmıştır. Görüntüler, sabit çalışma koşullarına ulaşıldıktan sonra alınmıştır. Tasarlanan deney sisteminde kullanılan ekipmanların teknik özellikleri Tablo 1'de verilmiştir. Soğutma sisteminden ve yapay kaçakların oluşturulduğu noktalardan termal kamera ile görüntü alma işlemi Şekil 2'de gösterilmiştir. 

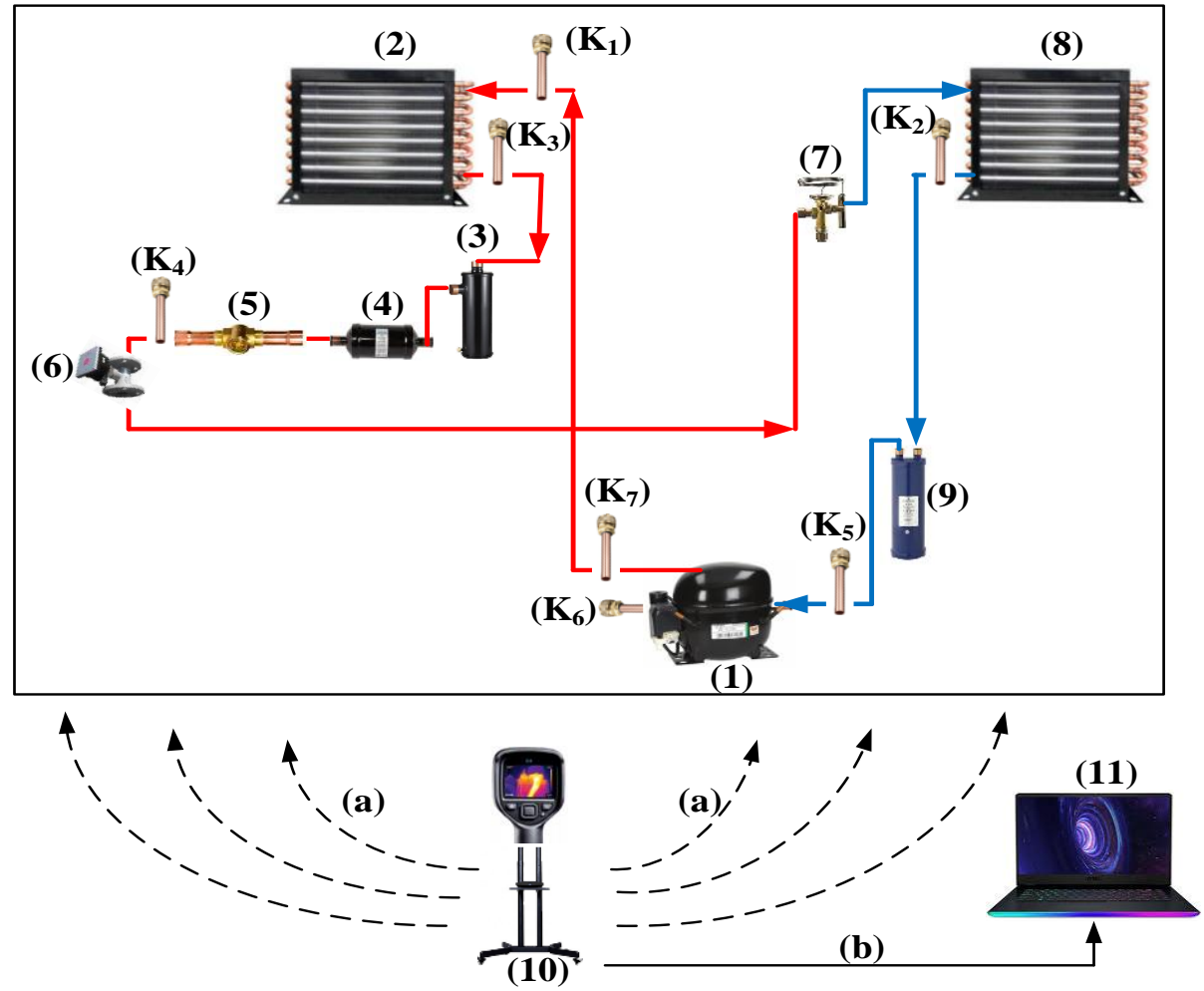

$\begin{array}{llllll}1 & \text { Kompresör } & 8 & \text { Evaporatör } & \mathrm{K}_{1} & \text { Kondenser girişi yapay kaçak noktası } \\ 2 & \text { Kondenser } & 9 & \text { Likit tutucu } & \mathrm{K}_{2} & \text { Evaporatör çıkışı yapay kaçak noktası } \\ 3 & \text { Sıvı deposu (receiver) } & 10 & \text { Termal kamera } & \mathrm{K}_{3} & \text { Kondenser çıkış1 yapay kaçak noktası } \\ 4 & \text { Drayer-kurutucu } & 11 & \mathrm{PC} & \mathrm{K}_{4} & \text { Drayer çııı̧ı yapay kaçak noktası } \\ 5 & \text { Gözetleme camı } & \mathrm{a} & \text { Termal kamera ile görüntü alınması } & \mathrm{K}_{5} & \text { Kompresör girişi yapay kaçak noktası } \\ 6 & \text { Akışölçer } & \mathrm{b} & \text { Veri aktarımı } & \mathrm{K}_{6} & \text { Servis borusu yapay kaçak noktası } \\ 7 & \text { TGV } & & & \mathrm{K}_{7} & \text { Kompresör çıkış1 yapay kaçak noktası }\end{array}$

Şekil 1. Deney sistemindeki ekipman, yapay kaçak noktaları ve termal kameranın pozisyonu

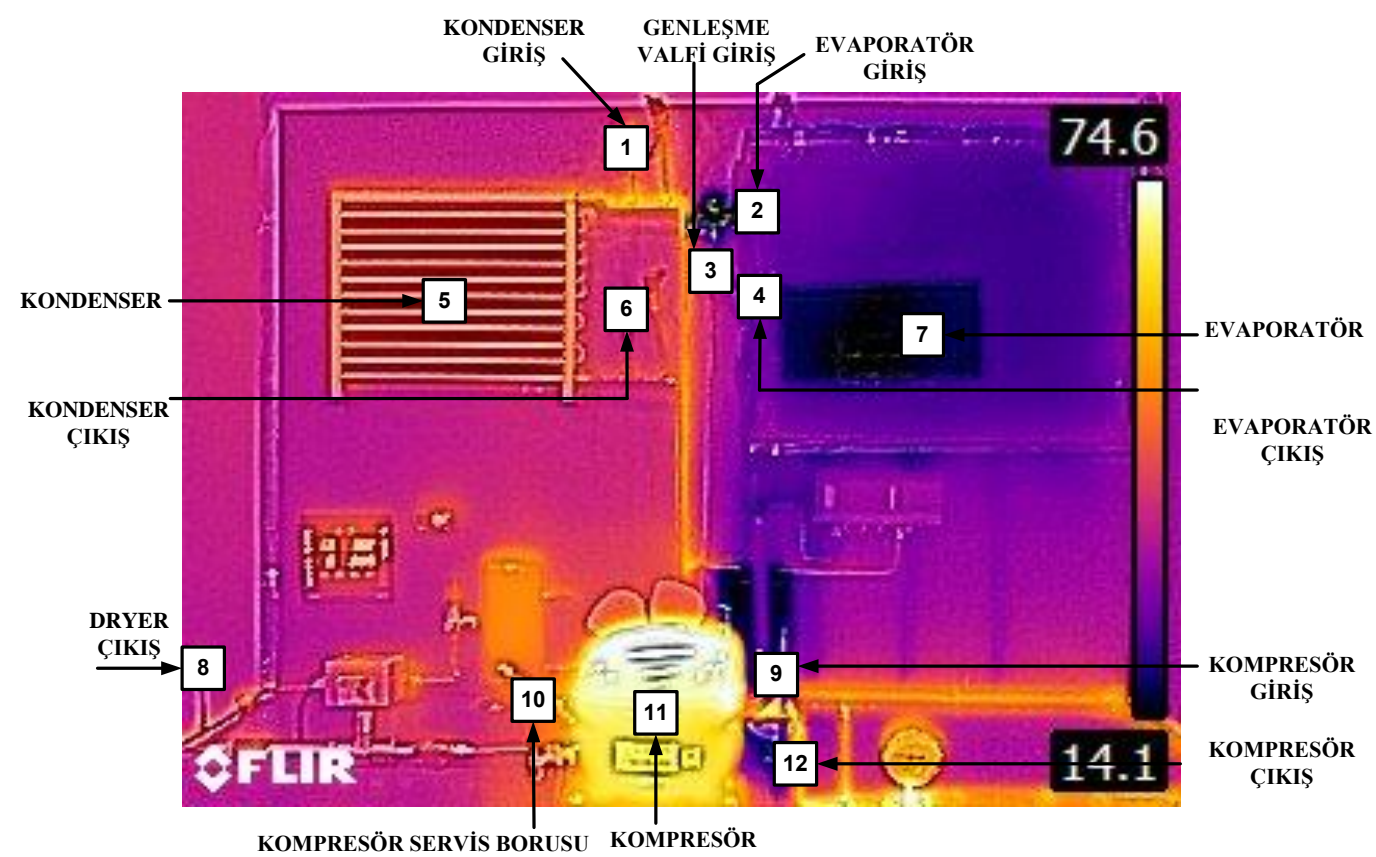

Şekil 2. Soğutma sisteminden ve yapay kaçak oluşturulan bölgelerden alınan termal görüntüler 
Tablo 1. Deney düzeneğinde kullanılan ekipmanların özellikleri

\begin{tabular}{|c|c|c|c|c|}
\hline $\begin{array}{l}\text { Ekipman ve } \\
\text { Sensörler }\end{array}$ & Voltaj & Ak1m & Güç & Teknik Özellikler \\
\hline Kompresör & $220-240 \mathrm{~V}$ & & $1 / 2 \mathrm{Hp}$ & Embraco NEU 6215 GK - Hermetik pistonlu, Akışkan: R22 \\
\hline Kondenser & $220-240 \mathrm{~V}$ & & 3/4 Hp & Karyer KT- hava akışlı \\
\hline Evaporatör & $220-240 \mathrm{~V}$ & & $1 / 2 \mathrm{Hp}$ & Karyer KT- hava akışlı \\
\hline Genleşme Valfi & & & & $\begin{array}{l}\text { DuNan TGV TIS dıştan dengeli rakorlu, Tek yönlü } \\
\text { PS } 46 \text { bar, Akışkan: R22, Çalışma aralığı: }-40 /+10{ }^{\circ} \mathrm{C}\end{array}$ \\
\hline Sivı Deposu & & & & $\begin{array}{l}\text { ESS-LRY } \\
\text { Basınç: } 32 \text { bar, Çalışma aralığı: } 0 /+70{ }^{\circ} \mathrm{C} \text {, Hacim: } 1.1 \mathrm{~L}\end{array}$ \\
\hline Likit Tutucu & & & & SAN XIN SX-204 \\
\hline Drayer & & & & Sanhua DTG, Kaynaklı, Çalışma aralığı: $-40 /+120^{\circ} \mathrm{C}$ \\
\hline Gözetleme camı & & & & SARCOOL kaynaklı \\
\hline Termal kamera & $\begin{array}{l}\text { AC adaptör } \\
\text { 90-260V } \\
\text { AC giriş } \\
\text { Kameraya } 5 \mathrm{~V} \\
\text { DC çıkış }\end{array}$ & & & $\begin{array}{l}\text { FLIR E8-XT, Kızılötesi çözünürlük (IR): } 320 \times 240(76800 \\
\text { piksel), Termal hassasiyet: }<0.05^{\circ} \mathrm{C} /<50 \mathrm{mK} \\
\text { Minimum odak uzaklığ } 1: 0.5 \mathrm{~m} \text {, Termal duyarlılık: }<0.06^{\circ} \mathrm{C} \text {, } \\
\text { Nesne sıcaklık aralığı: }-20 /+5500^{\circ} \mathrm{C} \text {, Doğruluk: }+10^{\circ} \mathrm{C} \text { ile } \\
+35^{\circ} \mathrm{C} \text { arasındaki ortam sicaklığ } 1 \text { ve }+0{ }^{\circ} \mathrm{C} \text { üzerindeki nesne } \\
\text { sıcaklığ } 1 \text { için } \pm 2{ }^{\circ} \mathrm{C} \text { veya okumanın } \pm 2 \% \text { 'si }\end{array}$ \\
\hline Akış ölçer & $12-24 \mathrm{~V}$ DC & 4-20 mA & & $\begin{array}{l}\text { Bass- TDSS.004.015.D.A.10.S.S.N.N } \\
\text { Ölçme Aralığ : } 0,6 \ldots 4,5 \text { 1/dk, Hassasiyet : \% } 1 \text { T.S. } \\
\text { Sicaklık : }-40 \ldots 120^{\circ} \mathrm{C}, \text { Basıç : } 63 \text { bar max. }\end{array}$ \\
\hline $\begin{array}{l}\text { Soğutucu akışkan } \\
\text { kaçak dedektörü }\end{array}$ & & & & $\begin{array}{l}\text { Testo 316-4, HCFC, HCF, CFC soğutucu akışkanları } \\
\text { Ölçüm parametresi: g/yıl, reaksiyon zamanı: } 1 \text { saniye } \\
\text { Kaçak alarmı: optik ve sesli alarm } \\
\text { Çalışma sıcaklığı: }-20 /+50{ }^{\circ} \mathrm{C} \text {, çalışma nemi: } 20-80 \text { \%RH }\end{array}$ \\
\hline
\end{tabular}

Termal kamera ile alınan kızı̈ötesi görüntüler üzerinden kaçak noktalarının tespitinin doğru değerlendirilebilmesi ve karşılaştııılabilmesi için elektronik soğutucu akışkan kaçak dedektörü kullanılmıştır. Cihazda bir sensör vasıtasıyla soğutucu akışkan kaçağı oluştuğunda cihaz alarm vermektedir. Genellikle bilinmeyen bir kaçağı bulmanın en hızlı yoludur. Kaçak alanı daha sonra tam yerini doğrulamak için sabun çözeltisiyle kaplanarak yer tam olarak belirlenebilmektedir. Soğutma sisteminde oluşturulan yapay kaçak noktalarından kaçağın tespit edilebilmesi için kullanılan dedektör Şekil 3’te görülmektedir.

R22, soğutma ve iklimlendirme uygulamalarında bir çalışma akışkanı olarak yaygın şekilde kullanılmaktadır. Küresel ısınma etkileri, bu soğutucu akışkanın arıza veya yer değiştirmeden dolayı mevcut cihazlardan salınması sonucunda büyük oranda artmaktadır (Llopis, ve diğerleri, 2011). R22, farklı sıcaklıklarda çok çeşitli soğutma ve klima uygulamaları için uygundur. Çevresel etki açısından incelendiğinde, ODP değeri 0.055 olup, GWP değeri ise 1810 'dur (Linde, 2020).

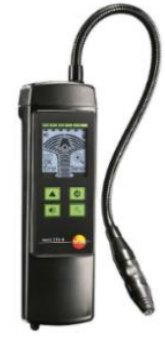

a) Kaçak dedektörü

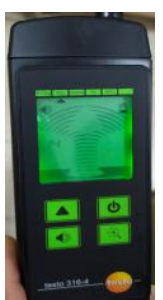

b) Normal çalışma durumu

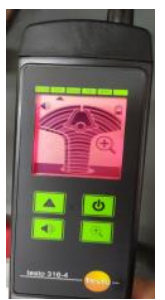

c) Kaçak tespit durumu

Şekil 3. Elektronik soğutucu akışkan kaçak dedektörü

\section{Pearson Korelasyon Benzerlik Analizi (PKBA) yöntemi ile soğutma sisteminde soğutucu akışkan kaçak tespiti}

Benzerlik ölçüleri nesneler arasındaki benzerlik derecesini hesaplamada kullanılan fonksiyonlardır ve benzerlik derecesi [0,1] veya [-1,1] aralığında yer almaktadır (Akpınar, 2014). Korelasyon iki nesnenin öznitelik değerleri arasındaki lineer ilişkinin yönünün ve gücünün belirlenmesinde en yaygın olarak kullanılan benzerlik ölçüsüdür (Ahlgren, 2003). x ve y veri dizileri arasındaki Pearson korelasyonu, $\mathrm{n}$ toplam nesne sayısı ve $\sigma_{x}$ ve $\sigma_{y}$ dizilerin standart sapması, $\bar{x}$ ve $\bar{y}$ dizilerin aritmetik ortalaması olmak üzere, aşağıdaki eşitlik kullanılarak hesaplanmaktadır. 
PearsonCorr $_{x y}=\frac{\sum_{i=1}^{n}\left(x_{i}-\bar{x}\right)\left(y_{i}-\bar{y}\right)}{(n-1) \sigma_{x} \sigma_{y}}$

Önerilen çalışmada, ilk olarak orijinal çalışan sistem ile karşılaştırma yapılacak yapay kaçak oluşturulmuş sistemlerden alınan termal görüntülerden her bir kesilmiş görüntü parçası için iki adet öznitelik matrisleri pearson korelasyonuna sokulmaktadır. Her bir görüntü parçası için, maksimum, minimum, ortalama sıcaklık ve bölge içinde kullanılan en yoğun sıcaklık değerleri olmak üzere 4 adet öznitelik değerleri kullanılmıştır. İkincil işlem olarak, her bir görüntü parçası için elde edilen Pearson korelasyon değeri bir eşik değere sokulmaktadır. Son işlem olarak, eşik değerin altında kalan görüntü parçasında kaçak vardır tespiti Eşitlik 2. de verilmiştir.

\section{If PearsonCorr Py $_{2}<$ Th, Kaçak var}

Else Kaçak yoktur

Eşitlik 3. de , seçilen bölgelerin maksimum ve minimum sıcaklık verilerinin elde ediliş yöntemleri sunulmuştur.

$$
\begin{aligned}
& T_{\text {max }}=\max \left(T_{\text {low }}+\left(T_{\text {high }}-T_{\text {low }}\right) * T_{-} I\right) \\
& T_{\text {min }}=\min \left(T_{\text {low }}+\left(T_{\text {high }}-T_{\text {low }}\right) * T_{-} I\right)
\end{aligned}
$$

Eşitlik 3 de ki $T_{-} I_{\text {, }}$ renkli kızılötesi görüntünün gri termal görüntüye dönüştürülerek elde edilen giriş görüntüsünü, $T_{l o w}$ ve $T_{h i g h}$ sıcaklık barının alt ve üst değerlerini göstermektedir.

Belirlenen bölgenin kızılötesi görüntüsünde yer alan sıcaklık değerlerinin ortalama değeri ise Eşitlik 4 de verilmiştir.

$$
T_{a v}=\frac{\sum_{i=1}^{M} \sum_{j=1}^{N} T_{\text {low }}+\left(T_{\text {high }}-T_{\text {low }}\right) * T_{-} I}{M * N}
$$

Eşitlik 4'teki M ve N kesilen bölgenin boyut bilgileridir. Belirlenen bölgenin kızılötesi görüntüsünde en yoğun sıcaklık değerini tespit etmek için seçilen bölgenin pikselleri için histogram oluşturulmuştur. Bu histogram sonuçlarında en yüksek değere sahip sıcaklık değeri seçilen en yoğun yüzey sıcaklık değeri olarak tespit edilmiştir. Tablo 1'de kaçak olmayan sağlam sistemden alınmış kızı̈ötesi görüntüdeki 12 alt bölgesi için elde edilmiş öznitelik matrisi verilmiş̧ir. Alt bölgelerin seçiminde, sisteme etkiyen elamanlar tercih edilmiş olup, bu elamanların giriş, çıkışları ve yüzey sıcaklık bölgeleri alınmıştır. Bu bölgelerdeki pikseller incelenerek, Maksimum Yüzey Sıcaklık (MakS), Minimum Yüzey Sıcaklık (MinS), Ortalama Sıcaklık (OS) ve En Yoğun Yüzey Sicaklık (EYYS) öznitelik verileri oluşturulmuştur.

Tablo 2. Kaçak olmayan sağlam kizll ötesi görüntüsü için elde edilen öznitelik matrisi

\begin{tabular}{l|l|l|l|l|l|l|l|l|l|l|l|l}
\hline Bölge & B1 & B2 & B3 & B4 & B5 & B6 & B7 & B8 & B9 & B10 & B11 & B12 \\
\hline MakS & 52,28 & 28,34 & 38,56 & 41,98 & 24,98 & 45,48 & 38,44 & 32,48 & 52,50 & 46,62 & 75,45 & 48,32 \\
\hline MinS & 44,64 & 27,14 & 38,56 & 41,98 & 22,63 & 40,59 & 26,77 & 20,58 & 50,68 & 37,75 & 68,51 & 48,32 \\
\hline OS & 50,86 & 27,51 & 38,56 & 41,98 & 23,78 & 44,02 & 31,20 & 25,17 & 51,36 & 45,28 & 71,38 & 48,32 \\
\hline EYYS & 52,00 & 27,00 & 39,00 & 42,00 & 24,00 & 44,00 & 32,00 & 21,00 & 51,00 & 47,00 & 71,00 & 48,00 \\
\hline
\end{tabular}

\subsection{Akış diyagramı ve Matlab GUI ara yüzünün tanıtımı}

Önerilen sisteminin akış şeması Şekil 4’te yer almaktadır. İlk olarak soğutucu akışkan kaçağı olmayan sistem görüntüsü ile yapay kaçak oluşturulmuş kızılötesi görüntüleri termal kamera ile alınmaktadır. İkinci aşamada bu iki kızılötesi görüntüler üzerinden öznitelik verileri çıartılarak her iki durum için özellik matrisi oluşturulmaktadır. İki özellik matrisi PKBA işlemine sokularak seçilen 12 bölgenin benzerlik değerleri elde edilmektedir. Son olarak, seçilen 12 bölgenin benzerlik değerleri \%75 eşik değeri ile karşılaştırılmaktadır. Bu eşik değerinden kü̧̈ük olması durumunda, ilgili bölgede "soğutucu akışkan kaçağı vardır" tespiti yapılmaktadır.

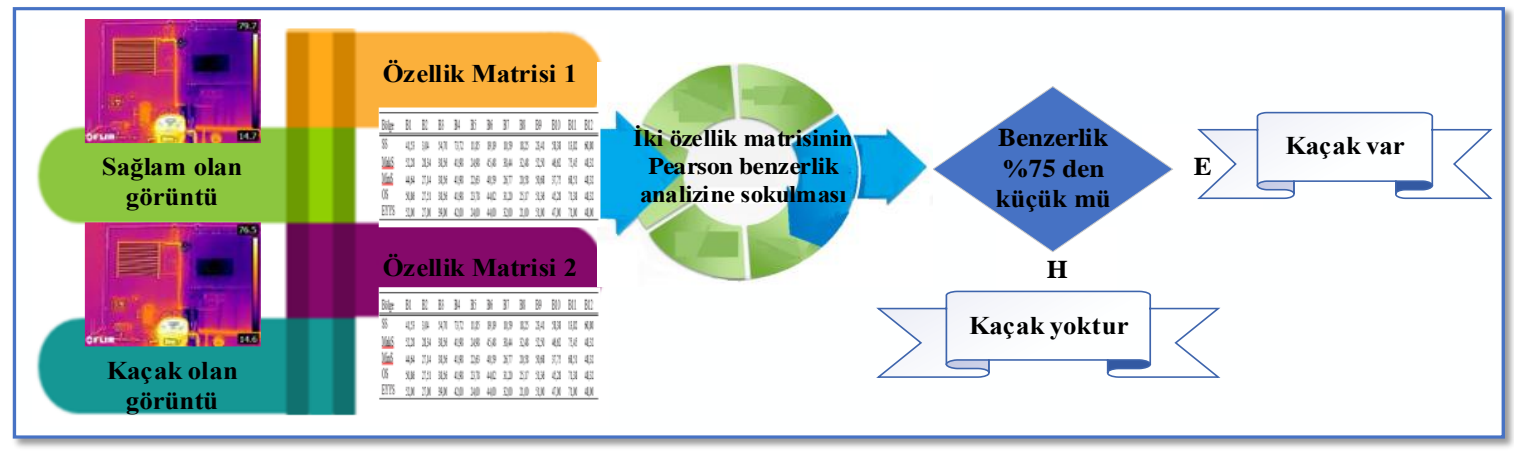

Şekil 4. Önerilen çalışmanın akış diyagramı 
Soğutucu akışkan kaçak tespiti Matlab GUI ara yüz ile gerçekleştirilmiş olup, Şekil $\mathbf{5}$ 'te genel görünümüne yer verilmiştir. İlk olarak, sağlam sistem görüntüsü ile karşılaştırılacak olan yapay kaçak kızılötesi görüntüsü yüklenerek, başlanmaktadır. Her iki kızı̈ötesi görüntüsünde yer alan sıcaklık bar göstergelerinin alt ve üst sıcaklık değerleri girildikten sonra, "Kesme_Orjinal" ve "Kesme_Kaçak" butonlarına basılır. Görüntülerin sol üst köşesi ve sağ alt köşesinden istenilen koordinat noktaları girilerek, kesme işlemi yapılmaktadır. Böylece deney setinin arka plan kısımları, sıcaklık bar göstergesi gibi istenilmeyen bölgeler kesilerek atılmaktadır. Bu işlemden sonra, kullanıcıdan kesilen görüntüyü kaç alt bölgeye ayırması gerektiği sorulur ve bunun için satır ve sütün bilgileri girilmektedir. Çalışmada bütün görüntüler 20x20 olmak üzere 400 alt bölge oluşturularak kaçak tespit işlemi gerçekleştirilmiş̧tir.

Bu tercih edilen bölgeler Șekil 2'de verilmiş olup, soğutma sistem elamanlarının giriș, çıkış ve yüzey bölgelerini kapsamaktadır. Görüntünün tamamını almayıp, sadece bazı bölgeler üzerinde çalışmanın temel amacı, işlem hızını artırmak ve analiz işlemlerine doğru yoğunlaşmayı gerçekleştirmek için yapılmıştır. Kullanıcı bölge numaralarını girdikten sonra, "KAÇAK ANALİZINEE BAŞLA" butonuna basarak kaçak tespit işlemini başlatmaktadır. Yöntemin analiz sonuçları ara yüzün sağ alt tarafında verilmektedir. Kaçak tespit sonuçları her seçilen bölgenin benzerlik değerini tablo ile kaçak olan bölgeyi ise yazılı olarak belirterek sunulmuştur.

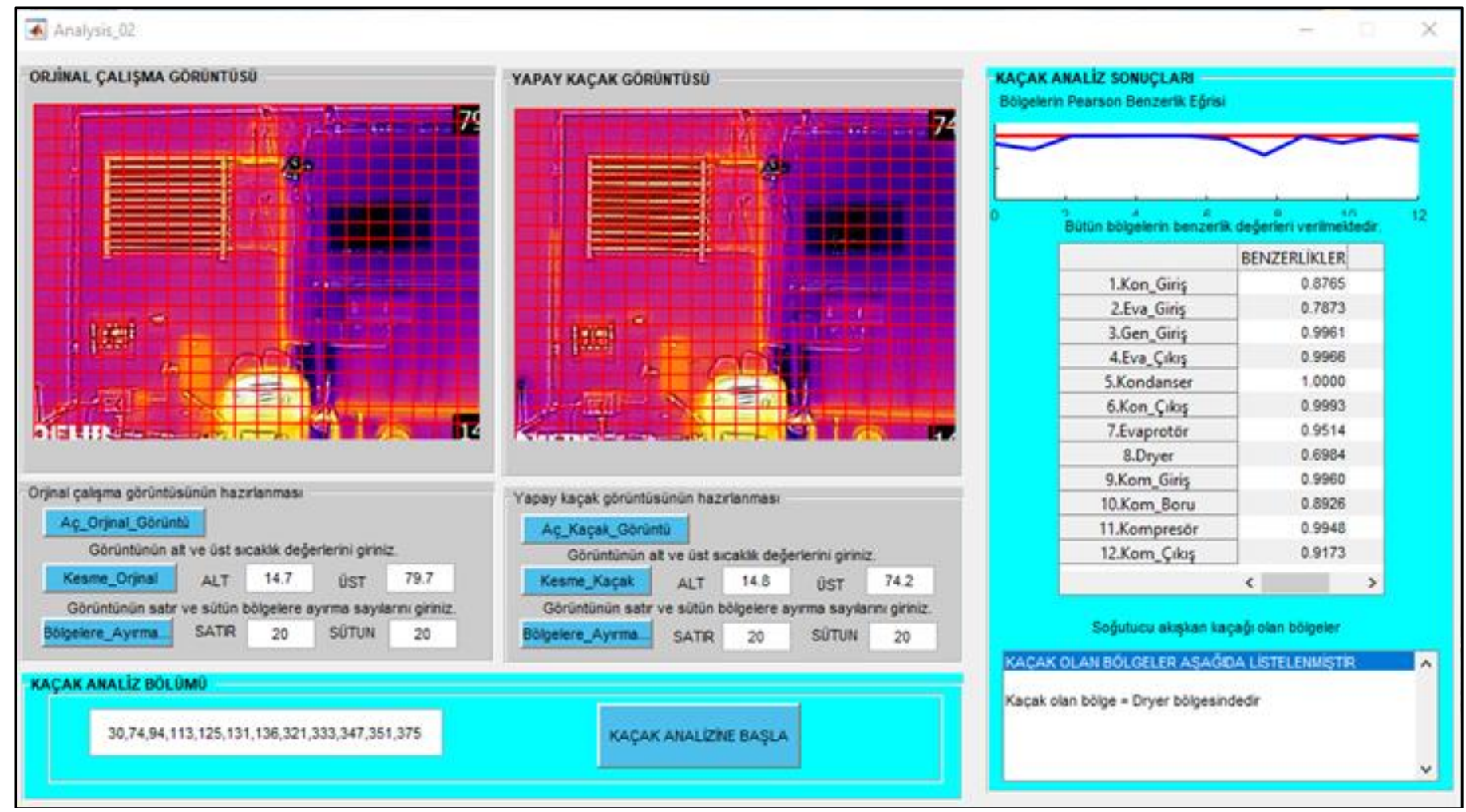

Şekil 5. Soğutucu aklşkan kaçak tespit işleminin Matlab GUI ara yüzü

\section{Araştırma Sonuçları ve Tartışma}

Önerilen çalışmada, soğutucu akışkan olarak R22 soğutucu akışkanı kullanılmış olup, 7 farklı bölgede yapay soğutucu akışkan kaçağı durumu oluşturulmuştur. Kaçak oluşturulmamış sistemin kızılötesi görüntüsü referans orijinal sağlam görüntü olarak alınmıştır. Şekil 6 b-h'de yer alan 7 kızılötesi görüntüleri oluşturulan yapay kaçak durumundan 5 dakika sonra alınmıştır. Her bir yapay kaçak test görüntüsü için 12 bölge belirlenerek 4 öznitelik elde edildikten sonra, PKBA işlemine sokulmaktadır. Tablo 3, PKBA işlemine sokulduktan sonra, 12 bölgenin referans görüntü ile benzerlik değerlerini vermektedir.

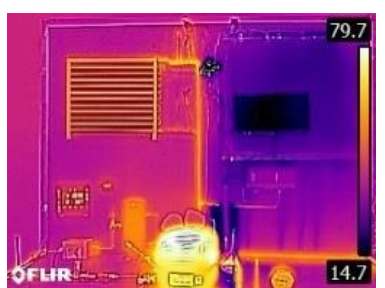

(a)

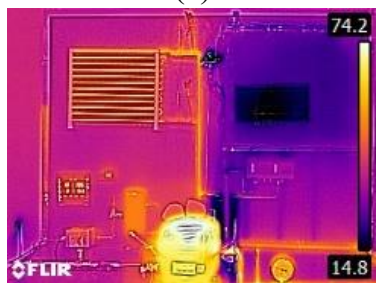

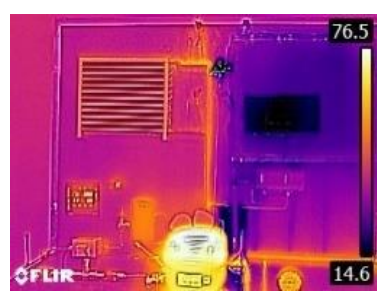

(b)

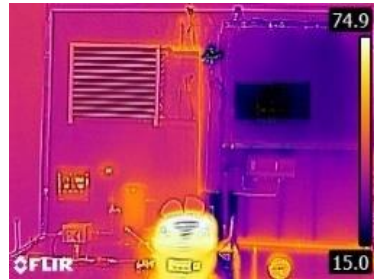

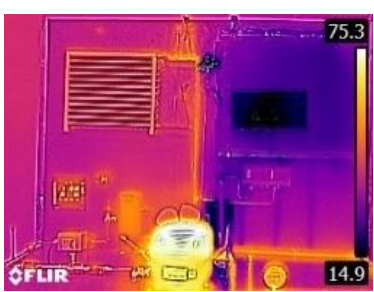

(c)

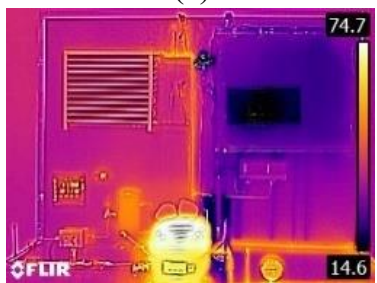

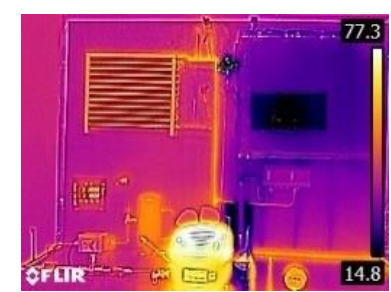

(d)

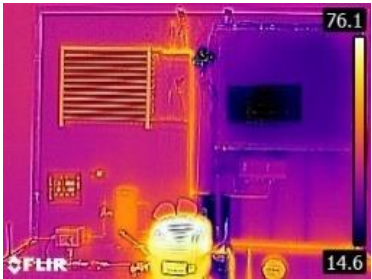


(a) Orijinal sağlam görüntü, (b) Kondenser girişinde kaçak görüntüsü, (c) Evaporatör çıklşında kaçak görüntüsü, (d) Kondenser çıkışında kaçak görüntüsü, (e) Dryer çıkışında kaçak görüntüsü, (f) Kompresör girişinde kaçak görüntüsü, (g) Kompresör servis borusunda oluşturulan kaçak görüntüsü, (h) Kompresör çıkışında oluşturulan kaçak görüntüsü

Çalışmada daha sonra oluşturulan yapay kaçak noktalarından elektronik soğutucu akışkan kaçak dedektörü ile kontrol gerçekleştirilmiştir. Tablo 3'te verilen benzerlik değerleri 0,75 'den küçük olan bölgelerde kaçak dedektörü uyarı vermiştir. Bu karşılaştırma ölçütü ile önerilen yöntemin kaçak dedektörü ile uyumlu davranış göstermiş olduğu teyit edilmiştir. Soğutma sisteminde oluşturulan yapay kaçakların elektronik soğutucu akışkan kaçak dedektörü ile tespit işlemi Şekil 7'de gösterilmiştir. Elektronik soğutucu akışkan kaçak dedektörü ile yapılan kontrollerde soğutucu akışkan kaçak tespiti tek bir noktada ise kısa süre içerisinde yeri tespit edilmiştir. Bunun yanında kaçak yerinin lokal olarak tespit edilebilmesi bu cihazların avantajı olarak görülmüştür. Kaçak yeri tespit edildikten sonra tekrar sisteme yaklaştırılmadan önce temiz bir ortamda sıfirlanarak kullanılması ayrıca bir zaman kaybı olarak göze çarpmaktadır. Birden fazla noktada soğutucu akışkan kaçağı olduğunda ise dedektör kaçağın yeri hakkında net bir tespit gerçekleştirememektedir. Ayrıca kullanılan soğutucu akışkan dedektörde tanımlı ise uyarı alınabilmektedir. Kayıtlı olmayan bir soğutucu akışkan kullanıldığında ise mevcut soğutucu akışkan kaçağının yeri tespit edilememektedir. Ortamda başka gazların kaçması ya da bulunması durumunda kaçağın yerinin tespit edilmesi zorlaşmaktadır. Kaçağın devam etmesi ile ortamda yayıldıktan sonra soğutucu akışkanın reaksiyonun azalmasını bekleyerek tekrar dedektör ile kaçağın tespiti yapılıncaya kadar geçen süre yine zaman kaybı olarak ortaya çıkmaktadır. Ayrıca soğutucu akışkan sektöründe gelişmeler ve yeni üretilecek her soğutucu akışkan için dedektör ve sensör temin edinilmesi ihtiyacı olması maliyeti artırıcı bir durum olarak göze çarpmaktadır. Karbon monoksit ve alkol, çoğu elektronik kaçak dedektörünün hassasiyetini olumsuz yönde etkileyebilmektedir. Kaçak tespit ederken hiçbirinin mevcut olmadığından emin olunmalıdır. Çoğu elektronik kaçak dedektörünün yanıcı veya patlayıcı gazlar içeren ortamlarda kullanılması önerilmez. Sensör son derece yüksek sıcaklıklarda çalışmaktadır. Bu sensör yanıcı bir gazla temas ederse, bir patlama meydana gelebilmektedir. Bu çok tehlikeli ve maliyetli olmaktadır. Olası bir kaçak durumunda ise elektronik kaçak dedektörü zarar görebilecektir.

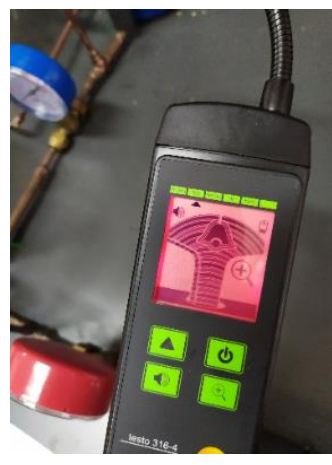

\section{Şekil 7. Sistem oluşturulan yapay kaçağın dedektör yardımıyla tespit edilmesi}

Tablo 3'ün sayısal sonuçlarına bakıldığında, oluşturulan yapay kaçak bölgelerinde benzerlik değerlerinin düştüğü gözlemlenmektedir. Örneğin kompresör giriş ve çıkış bölgelerinde yapay kaçak oluşturulmasında 0,5567 ve $-0,4231$ benzerlik değerleri ile kaçakları tespit edildiği doğrulanmaktadır. Oluşan soğutucu akışkan kaçağı bulunmuş olduğu ortamın minimum, maksimum, ortalama ve en yoğun yüzey sicaklık değerlerini değiştirmiştir. Bu değişim sayesinde, PKBA benzerlik değerlerinin bir eşik değer ile karşılaştırılarak kaçak bölgelerinin bulunabileceği kanıtlanmaktadır. Kaçak noktalarından görüntü alma süreleri uzadıkça tablodaki değerlerin daha düşük olacağı görülmektedir.

Tablo 3. Yapay kaçak durumlarında bölgelerin benzerlik değerleri

\begin{tabular}{c|c|c|c|c|c|c|c}
\hline $\begin{array}{c}\text { Seçilen Alt } \\
\text { Bölgelerin } \\
\begin{array}{c}\text { Benzerlik } \\
\text { Değerleri }\end{array}\end{array}$ & $\begin{array}{c}\text { Kondenser } \\
\text { Giriş }\end{array}$ & $\begin{array}{c}\text { Evaporatör } \\
\text { Çı1ş }\end{array}$ & $\begin{array}{c}\text { Kondenser } \\
\text { Ç1k1ş }\end{array}$ & Dryer & $\begin{array}{c}\text { Kompresör } \\
\text { Giriş }\end{array}$ & $\begin{array}{c}\text { Kompresör } \\
\text { Servis } \\
\text { Borusu }\end{array}$ & $\begin{array}{c}\text { Kompresör } \\
\text { Ç1k1ş }\end{array}$ \\
\hline B1 & $\mathbf{0 , 5 9 5 2}$ & 0,8763 & 0,9919 & 0,8765 & 0,9316 & 0,8029 & 0,9962 \\
\hline B2 & 0,9175 & 0,8971 & 0,9964 & 0,7873 & 0,7774 & 0,9916 & 0,9297 \\
\hline B3 & 0,8878 & 0,9778 & 0,9419 & 0,9961 & 0,8305 & 0,9563 & 0,9686 \\
\hline B4 & 0,9957 & $\mathbf{0 , 7 3 1 3}$ & 0,8599 & 0,9966 & 0,8893 & 0,9274 & 0,9799 \\
\hline B5 & 1,0000 & 1,0000 & 1,0000 & 1,0000 & 1,0000 & 1,0000 & 1,0000 \\
\hline B6 & 0,9856 & 0,8522 & $\mathbf{0 , 5 4 2 2}$ & 0,9993 & 0,9967 & 0,9413 & 0,9286 \\
\hline B7 & 0,9109 & 0,9965 & 0,8659 & 0,9514 & 0,9706 & 0,9159 & 0,9902 \\
\hline B8 & 0,8381 & 0,8350 & 0,8662 & $\mathbf{0 , 6 9 8 4}$ & 0,8486 & 0,9721 & 0,8086 \\
\hline B9 & 0,9903 & 0,9863 & 0,9889 & 0,9960 & $\mathbf{0 , 5 5 6 7}$ & 0,9060 & 0,9726
\end{tabular}




\begin{tabular}{c|c|c|c|c|c|c|c} 
B10 & 0,7588 & 0,9721 & 0,9297 & 0,8926 & 0,9281 & $\mathbf{0 , 6 9 1 1}$ & 0,9864 \\
\hline B11 & 0,9969 & 0,9598 & 0,8091 & 0,9948 & 0,8312 & 0,9951 & 0,9967 \\
\hline B12 & 0,9076 & 0,8390 & 0,9961 & 0,9173 & 0,7529 & 0,9971 & $\mathbf{- 0 , 4 2 3 1}$ \\
\hline
\end{tabular}

\section{Sonuç}

Önerilen çalışmada ticari tip soğutma sistemlerinde soğutucu akışkan kaçaklarının tespiti için kızılötesi görüntü işlemi yöntemi uygulanmıştır. PKBA ile elde edilen benzerlik değerlerinin bir eşik değerden geçirilerek yapılan bu kaçak tespit yöntemi soğutma sisteminde başarılı bir şekilde uzaktan gerçekleştirilebileceği ispatlanmıştı. Yapılan çalışmada kullanılan kızılötesi görüntüleme ile kaçak tespit sensörünün arıza arama yöntemine alternatif, ara yüz özelliği ile daha görsel çözüm yöntemi getirilmiştir. Sistem için geliştirilen yazılım, kullanıcı için kolay programlanabilir özelliktedir. En büyük dezavantajı referans orijinal görüntü ile kaçak oluşturulmuş görüntü bölgelerinin birbirine denk kesilme işleminin zor gerçekleştirilmesidir. Önerilen yöntemin endüstriyel uygulamalarda tercih edilen bir yöntem olması için, soğutma sisteminde kullanılan elamanların nesne tanıma işlemi katılarak kaçak analizi yapılması, ileride yapılması gereken çalışmalar olarak düşünülmektedir.

\section{Teșekkür}

Bu çalışma, TÜBİTAK tarafindan 218M936 numaralı projeyle desteklenmiştir.

\section{Kaynakça}

Ahlgren, P., Jarneving, B., \& Rousseau, R. (2003). Requirements for a cocitation similarity measure, with special reference to Pearson's correlation coefficient. Journal of the American Society for Information Science and Technology, 54(6), 550-560.

Akpinar, H. (2014). Data. Istanbul: Papatya.

Braun, J. E. (2003). Automated fault detection and diagnostics for vapor compression cooling equipment. J. Sol. Energy Eng., $125(3)$, $266-274$.

Corberán, J. M.-G.-B.-M.-P. (2011). Influence of the source and sink temperatures on the optimal refrigerant charge of a water-to-water heat pump. International Journal of Refrigeration, 34(4), 881-892.

Francis, C. M. (2017). An investigation of refrigerant leakage in commercial refrigeration. International Journal of Refrigeration, 74, 12-21.

Goswami, D. Y. (2001). Effect of refrigerant charge on the performance of air conditioning systems. International journal of energy research, 25(8), $741-750$.

Grace, I. D. (2005). Sensitivity of refrigeration system performance to charge levels and parameters for online leak detection. Appl. Therm. Eng., 25(4), 557-566.

Katırcıoğlu, F. Ç. (2019). Infrared image enhancement model based on gravitational force and lateral inhibition networks. Infrared Physics \& Technology, 100, 15-27.

Kocyigit, N. B. (2014). Fault diagnosis of a vapor compression refrigeration system with hermetic reciprocating compressor based on ph diagram. International journal of refrigeration, 45, 44-54.

Koronaki, I. P. (2012). Refrigerant emissions and leakage prevention across Europe-Results from the RealSkillsEurope project. Energy, 45(1), 71-80.

Linde. (2020). Linde gas. Mays 26, 2020 tarihinde wttps://www.lindegas.com/en/products_and_supply/refrigerants/hcfc_refrigerants/r22/index.html.

Llopis, R., Cabello, R., Sánchez, D., Torrella, E., Patiño, J., \& Sánchez, J. G. (2011). Experimental evaluation of HCFC-22 replacement by the dropin fluids HFC-422A and HFC-417B for low temperature refrigeration applications. Applied Thermal Engineering, 31(6-7), 1323-1331.

Madani, H. \&. (2014). A comprehensive study on the important faults in heat pump system during the warranty period. International journal of refrigeration, $48,19-25$.

Mota-Babiloni, A. N.-E.-C. (2015). Commercial refrigeration-an overview of current status. International journal of refrigeration, 57, $186-196$.

Poggi, F. M.-T. (2008). Refrigerant charge in refrigerating systems and strategies of charge reduction. International Journal of Refrigeration, 31(3), 353-370.

project, R. S. (2020). http://www.realskillseurope.eu/.

project, R. Z. (2020). http://www.realzero.org.uk/.

Ramschie, A. A. (2017). Method of Freon Leak Detection and Dirty Air Filter in Air Conditioning for Electrical Savings. International Journal of Computer Applications, 172(1), 35-40.

Rossi, T. M. (2004). Unitary air conditioner field performance.

Takeuchi, S. \&. (2018). Fault Diagnosis Method Based on Scaling Law for On-line Refrigerant Leak Detection. I. 2. (ICMLA), $1087-1094$.

Tassou, S. A. (2005). Fault diagnosis and refrigerant leak detection in vapour compression refrigeration systems. . International Journal of Refrigeration, $28(5), 680-688$.

Union, O. J. (2007). Commission Regulation (EC) No 1516/2007, no. L335/10. Brussels.

Yoo, J. W. (2017). Refrigerant leakage detection in an EEV installed residential air conditioner with limited sensor installations. International Journal of Refrigeration, $78,157-165$. 